\title{
VALUE STREAM MAPPING: CASE STUDY IN COLUMNS CONCRETING
}

\author{
Andrezza V.C. Germano ${ }^{1}$, Nayara Jhéssica M. Fonsêca ${ }^{2}$, Reymard Sávio S. Melo ${ }^{3}$, Artur \\ Moura $^{4}$
}

\begin{abstract}
Based on the principles of lean thinking, originated from the automobile industry, which seek to eliminate waste, practice continuous improvement and add value to the product from the perspective of the customer, some adaptations have been made to apply the philosophy of lean production in construction. Thus, this paper aims to propose improvements in the concrete placing process using Value Stream Mapping. Therefore, the research strategy adopted was the exploratory case study. The results suggest that the columns concreting process lead time could be potentially reduced from five hours and nineteen minutes to two hours and four minutes.
\end{abstract}

Keywords: Lean construction, continuous flow, value stream mapping.

\section{INTRODUCTION}

Architecture, Engineering and Construction (AEC) industry is a scenario that is more complex than other industries (Koskela, 1992). Problems related to productivity, job safety, labour shortages and the lack of working conditions are commonly observed in such sector. Such context has motivated several researches that seek to solve problems faced in the context.

The five basic principles of lean thinking highlighted by Womack and Jones (1998) are: Specify value from the standpoint of the end customer; Identify value flow, Flow, Pull, and Perfection. Picchi (2003) further emphasises that the experience of other industrial sectors shows that the simplicity of the flow principle, using the Value Stream Mapping (VSM), is an important way to provide a systemic view.

Several studies have applied VSM to improve construction processes. More recently, Rosenbaum et al. (2014) applied VSM as a green-lean approach in the construction of a hospital to improve its environmental and production performance during the structural concrete work stage.

Shou et al. (2016) conducted a systematic literature review aiming to identify critical success factors in the VSM implementation across five sectors: manufacturing, healthcare, construction, product development, and service. A total of 97 journal papers were identified by the authors between 1999 and 2015. Results showed that the majority, 72 papers, are related to VSM implementation in the manufacturing industry, and only

1 Master's Student, Graduate program in Civil Engineering, Federal University of Rio Grande do Norte, Natal, RN, Brazil, andrezza.coutinho@hotmail.com

2 Master's Student, Graduate program in Civil Engineering, Federal University of Rio Grande do Norte, Natal, RN, Brazil, jhessica_marques5@hotmail.com

3 Assistant Professor, Civil Engineering Dept., Federal University of Rio Grande do Norte, Natal, RN, Brazil, smelo@ct.ufrn.br

4 Civil Engineer, Construtora Constel, Natal, RN, Brazil, arturmoura@constell.com.br 
eight papers are related to VSM implementation in the construction industry. However of those eight papers, only one (Yu et al., 2009) seeks to standardize the variety of production by reducing waste in construction processes.

This paper aims to apply the VSM methodology to improve the concrete placing process in a Brazilian construction site. The mobile pump is a concrete placing method commonly practiced in Brazil. In this concrete placing method, the placing rate is dependent on the pumping rate, the continuity of concrete supply, and the capacity of the placing gang (Lu and Anson, 2004).

In this sense, this paper seeks to answer the following question: "How to improve the stream of materials and information in the process of concreting columns?"

\section{LITERATURE REVIEW}

\subsection{Principles of lean thinking related to concreting process}

The new production philosophy proposed by Koskela (1992) considers production as a stream of material and/or information from raw material to final product. In this flow, there are conversion activities and flow activities, which represent value adding and non-value adding activities distributed throughout the flow.

The main idea of this production philosophy is to reduce or eliminate flow activities and increase the efficiency of conversion activities. From this analysis, Koskela (1992) proposed eleven principles to improve the design of production systems: Reduce the share of non-value-adding activities; Increase output value through systematic consideration of customer requirements; Reduce variability; Reduce the cycle time; Simplify by minimizing the number of steps, parts and linkages; Increase output flexibility; Increase process transparency; Focus control on the complete process; Build continuous improvement into the process; Balance flow improvement with conversion improvement; Benchmark.

Of the aforementioned principles, four of them deserve special attention in the concreting process: reduction of non-value-adding activities, reduction of process cycle time, increase of process transparency (transparent work environment are susceptible to observation) and continuous improvement (effort to reduce wastes and increase value in process management should be conducted continuously with the participation of the responsible team).

\subsection{Wastes}

In order to keep production in a continuous flow, Ohno (1988) proposed seven types of wastes that compromise the value stream: transportation, inventory, motion, waiting, over-processing, over-production and defects.

Those required to understand this research are: overproduction (producing a given product in quantities greater than those needed to satisfy demand), waiting (idle time of material, machine, information or equipment), defects (components or products that do not meet the specification), available inventory (early production leads to the generation of stocks that are stagnant at different points in the value chain), unnecessary movement (exit of employees from their work environment in search of materials, tools, work instructions and/or help). Moreover, Koskela (2004) proposed the eighth type of waste: making-do (or improvisation) refers to a situation where a task is started without all its standard input has ceased. 


\subsection{Value Stream Mapping}

Value stream mapping is a qualitative tool that describes in detail how the productive unit should operate to create a stream. Originally, VSM was conceived as a lean production management technique, which consists of the elaboration of maps that represent the value stream of a specific product family (Rother and Shook, 1999). Therefore, VSM is a tool to fight waste and reduce lead time, communication, business planning and that manages the process of change.

The material flow is the movement of material inside the construction site and the information flow tells each process what to manufacture or what to do next. Some specific VSM concepts that were used in this research are presented in Table 1.

Table 1: VSM Concepts.

\begin{tabular}{|c|c|}
\hline Concept & Meaning \\
\hline Push system & $\begin{array}{c}\text { Production system in which each process tries } \\
\text { to produce the maximum quantity of possible } \\
\text { units (demand forecast). }\end{array}$ \\
\hline Pull system & $\begin{array}{r}\text { Production system in which each process } \\
\text { produces only what the next one requires } \\
\text { (actual demand). }\end{array}$ \\
\hline Cycle time & $\begin{array}{c}\text { Frequency with which a part or product is } \\
\text { completed by a process. }\end{array}$ \\
\hline Value adding time & $\begin{array}{c}\text { Time of the work elements that actually } \\
\text { transform the product in such a way that the } \\
\text { customer is willing to pay. }\end{array}$ \\
\hline Lead time & $\begin{array}{c}\text { Time required for a product to move through } \\
\text { all stages of a process, from start to finish. }\end{array}$ \\
\hline Kaizen events & $\begin{array}{c}\text { A concentrated effort to solve production } \\
\text { problems and improve the value flow. }\end{array}$ \\
\hline
\end{tabular}

Source: Adapted from Rother e Shook (1999).

\section{RESEARCH METHOD}

An exploratory case study was adopted as the research strategy. Case study is appropriate to answer "why" and "how" questions, and also when the researcher has little or no possibility of controlling the events, or even when general circumstances of the phenomenon to be studied are contemporary, in a context of real situation (YIN, 2001).

Construct validity was addressed through the data triangulation from multiple sources of evidence: direct observation, interviews and documents. External validity is related to analytical generalizations, in which the researcher seeks to generalize a particular set of results to a more comprehensive theory.

VSM implementation stages are: (i) selection of a family of products, (ii) map the current state (collection of information at the construction site), (iii) map the future state (state to be achieved) and (iv) preparation of a work and implementation plan that describes how to achieve the future state. In both current and future states, icons are used to represent material and information flows. The data collected in the current state 
mapping were value-adding time, cycle time, and lead-time. The future state map was later reviewed by the company's construction planning director.

\section{RESULTS AND DISCUSSIONS}

\subsection{Case study}

The selected company is a medium-sized real estate developer in Natal/Brazil. The project under study was a 27-storey residential tower. It was mapped the stage of columns concreting of the second level below ground. It is worth mention that the concrete work should already be running on the tenth floor according to the project planning. The project delay was due to legal problems related to the project's neighbourhood, which started during the foundation stage.

Given the evidences obtained that indicate cycle times, inventories generated throughout the work execution, number of workers involved in each process and, according to the discussion about respective causes, it was possible to draw the current state map of the columns concreting work (Figure 1).

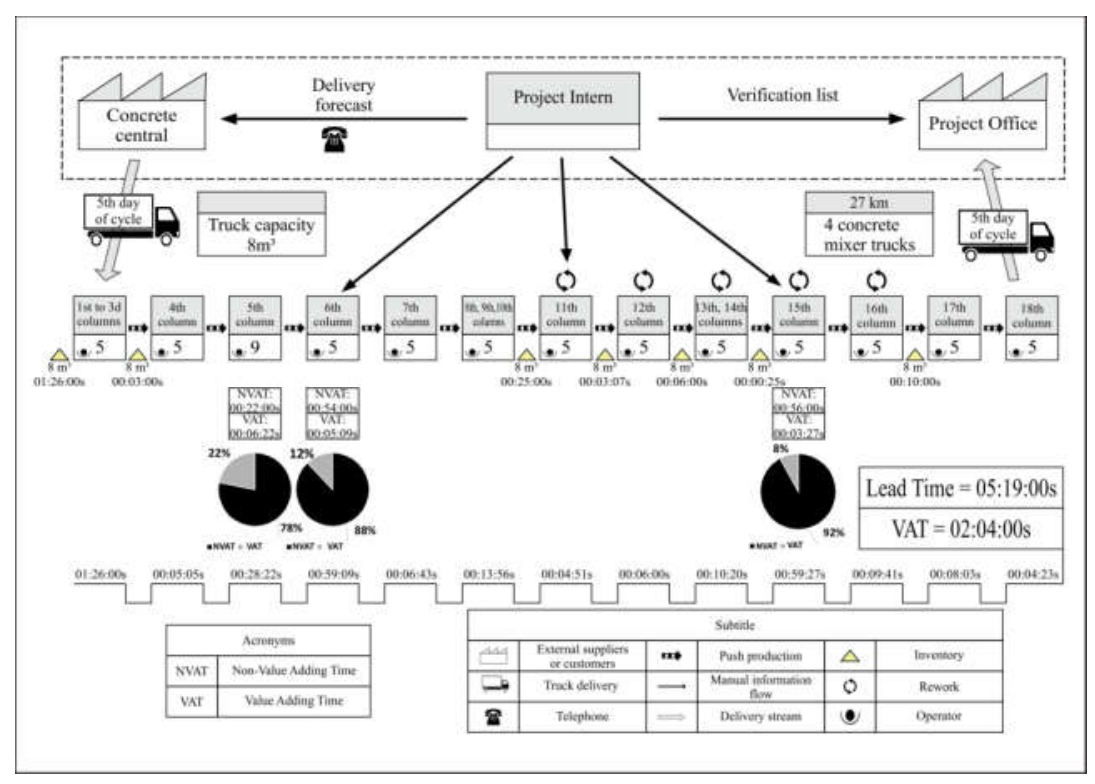

Figure 1: Current state map.

As established by the weekly planning, the columns concreting work should start at 7:00 a.m. The pumping machine arrived at the construction site after a 15-minute delay. The concrete mixer truck arrived at the site only at 7:50 a.m. due to bad traffic conditions. Each concrete mixer truck was fully charged, carrying $8 \mathrm{~m}^{3}$ of concrete.

A further 26 minute-delay occurred due to improper positioning of a backhoe in the construction site that prevented the concrete mixer truck from parking inside the site. This indicates non-compliance with restrictions that should be eliminated in advance to ensure flow continuity with subsequent activities. Consequently, the concreting work began at 8:26 a.m.

During the concreting pouring process, some interruptions occurred due to the truck's arm size. The truck's arm was too small to reach the columns formworks far from the truck (Figure 2.a). Such problem happenned due to the lack of a site layout design, by 
means of which it would be possible to specify the exact arm's length and hose necessary for the concreting of all the pavement columns, without interruptions, improvisations or excess in the number of workers (Figure 2.b) to complete the work.

The insufficient size of the hose for concreting the more distant formworks resulted in improvisations that led to a considerable increase in cycle times. Figure 2.b shows improvisation where a wooden board was used without success to prevent the concrete from being thrown out of a column formwork. Thus, the concrete placing activity was performed by workers.

After the concreting of 15 columns (the amount possible with the initial arm and hose), a 30-minute interruption occurred. Five workers installed an extension in the hose consisting of a metal tube of difficult handling due to the high weight and the high material rigidity. Such interruption reduced the workers production rate, making the work slower and configuring an activity that clearly does not add value to the product.

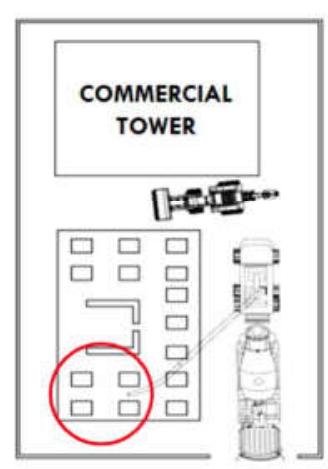

(a)

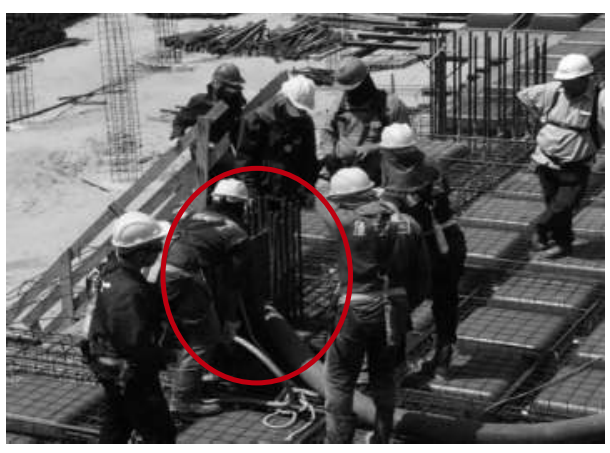

(b)

Figure 2: Construction site layout (a) and making-do in concrete placing process.

During the concreting of the fifth column, the connection of the hose to the arm of the pumping machine broke, resulting in another interruption that lasted twenty-two minutes to repair the equipment and involved nine employees including the site manager and an intern.

Another interruption commonly observed was due to the waiting for the following batch of concrete. An intern performed the release order of the following batch of concrete from the concrete plant by the time the previous batch of concrete arrived in the construction site. Nevertheless, the transportation time of batches varied significantly between 26 and 50 minutes, generating great waiting times during the work.

The intern also documented (in his own way, since there is no standard document for this type of control) the arrival and departure times of concrete mixer trucks, as well as the columns formwork filled with concrete.

It can be noticed that a push production system is adopted, since the request of batches of concrete is carried out through a demand forecast, which involves low reliability and can generate waste. In fact, the company requested four batches of $8 \mathrm{~m}^{3}$ of concrete, and only three batches were sufficient to concrete the eighteen columns. That is, a full batch of the four batches requested was unnecessary for the work in process. Therefore, without prior planning, the project team decided to concrete others structural elements such as some columns of the commercial tower that is part of the project and part of the curtain wall foundations. 
Another identified waste was the excess of workers involved in the work execution. Two workers were still handling the concreting hose, while two others were handling the vibrator and another one was operating the truck arm.

In view of the current state conditions, a series of improvements are proposed to eliminate the identified wastes, making the flow continuous, eliminating interruptions, reducing cycle times and the percentage of non-value adding activities and, ultimately reducing lead time. The future state map is presented in Figure 3.

The first suggested improvement refers to the change of the push production system into a pull production system, so that the subsequent processes trigger the execution of previous processes, based on the actual batch demand of concrete, avoiding the occurrence of overproduction.

It is suggested to use spreadsheets with the actual volumes required for each formwork to be filled with concrete (data obtained through the structural design itself). It is also suggested that the site manager review the data collected by the intern.

Another fundamental improvement consists in the elaboration of a detailed site layout design, through which it is possible to extract accurate information, such as distances and available space for the movement of people, materials, machinery and equipment. The use of this information should make it possible to know the required lengths of both the pumping machine arm and the concreting hose to avoid wasting time by trying to push these tools to the most distant columns without success and to avoid improvisation as was observed in the current VSM.

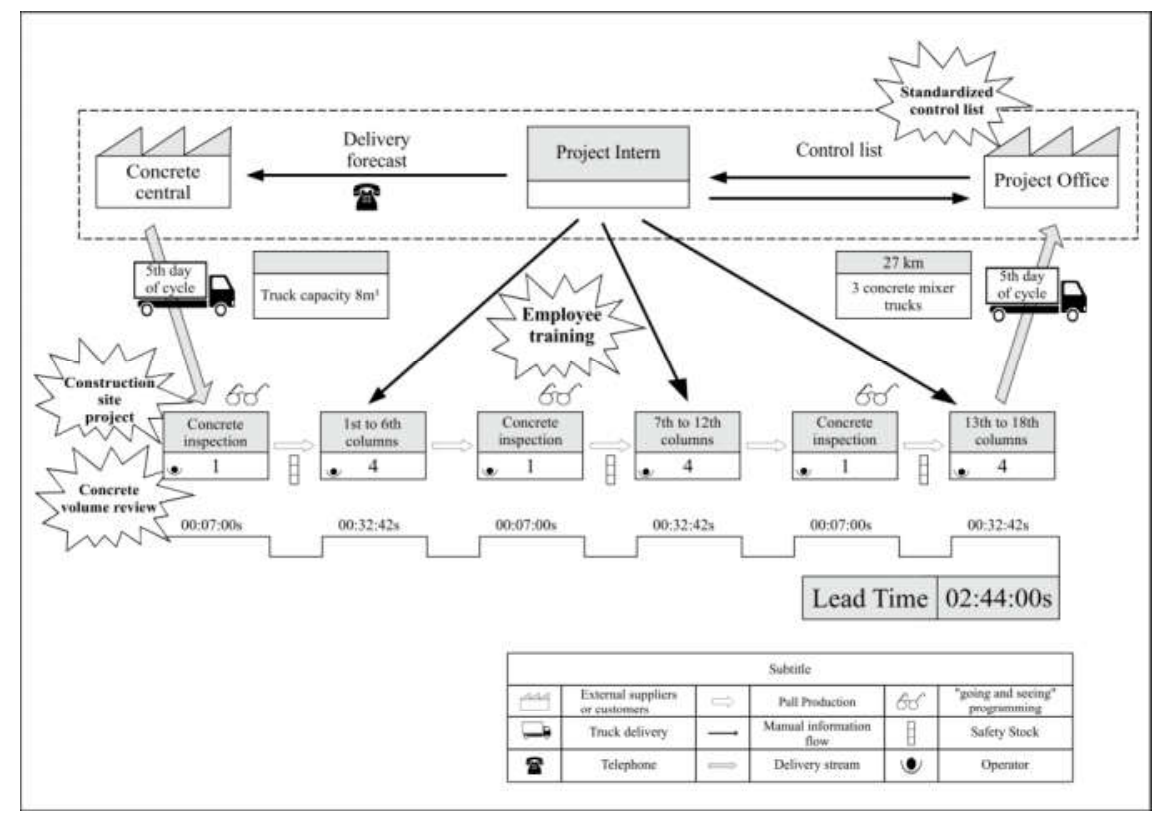

Figure 3: Future state map.

After the last work performed before the concreting, the organization of the construction site must be carried out, so that all the restrictions regarding moving space are solved, so that, without waiting-related wastes, machines used for the concreting work can be placed in the workplace and start the work.

After the arrival of each batch of concrete at the construction site, it is suggested that, in parallel to the collection of a sample of concrete for carrying out standards tests, a 
trained professional goes to gemba ("go and see" principle) and check the hose connection to ensure that decoupling accidents do not occur during the concreting execution.

A kaizen can be applied by a technical training and collaboration developed with the workers in order to make them more proactive and work collaboratively. This should enable a reduction from five to four workers involved in the concreting process, in which two workers should handle the hose, another one should handle the vibrator and the fourth worker should control the pump arm movement.

Another kaizen consists of the elaboration of a standardized control list. This list would include: (i) arrival and departure times of the concrete batches; (ii) start and finish dates of concrete work activities and (iii) information indicating which columns formwork was filled by each batch of concrete. The standardization of such control tool should provide greater processes transparency, in order to make information clearer and more comprehensible, regardless of the worker involved in the concrete filling process. The document should always be forwarded to the office and planning teams to support the preparation of plans.

As previously mentioned, the concrete transportation time from the concrete plant to the construction site was highly variable and can hardly be controlled, since it represents an external factor with a high degree of uncertainty. However, the VSM aims to delineate the ideal state for execution of a given work. Therefore, the estimated times in the future state map for such transportation are equal to the lowest observed time, during the mapping of the current state. In order to avoid flow interruptions, a "safety stock" could be used to minimize the effects of eventual delays by the concrete supplier. Safety stock represents goods held at any point (raw materials, work in process, or finished goods) to prevent downstream customers from being starved by upstream process capability issues (Lean Enterprise Institute, 2011).

This safety stock will be guaranteed by means of a ready-mixed concrete truck, with a volume of $8 \mathrm{~m}^{3}$ of concrete that will accompany the previous trucks in the concreting process, allowing a continuous supply of concrete after the discharge of the previous truck. This could potentially eliminate interruptions due to truck delays or due to failures in previous processes.

Finally, it is noted that lead time could be reduced by approximately $50 \%$, from 5 hours and 19 minutes in the current state, to 2 hours and 44 minutes in the future state, proving the achievement of the established goal for this work.

\section{CONCLUSIONS}

The use of VSM in the columns concreting process allowed the identification of six types of waste: waiting, handling, inventory, overproduction, rework and making-do. The improvements opportunities showed in the future state map would eliminate or reduce the interruptions observed in the process flow, making it continuous, and reducing the cycle times and the lead-time of the columns concreting work.

One limitation of this study is that the authors did not include the works that precede the concrete placing process, which could explain the delay in the project schedule and propose improvements that may support future planning and execution. An additional future study would be to elaborate and test an implementation plan for the future state map developed in this paper. 


\section{ACKNOWLEDGMENTS}

The authors would like to thank the company that provided data for this study.

\section{REFERENCES}

Koskela, L. (1992) Application of the new production philosophy to construction. Stanford University, CIFE Technical Report.

Koskela, L. (2004). Making-do. The eighth category of waste. In: Annual Conference of the International Group for Lean Construction, 12, Helsingor.

Lean Enterprise Institute (2011). Lean Lexicon: A Graphical Glossary for Lean Thinkers.

Lu, M.; Anson, M. (2004). Establish Concrete Placing Rates Using Quality Control Records from Hong Kong Building Construction Projects. Journal of Construction Engineering and Management, v.130, n 2, pp.547-554

Ohno, T. (1988). Toyota production system: beyond large-scale production. New York: Produtivity Press.

Picchi, F. A. (2003) Oportunidades da aplicação do Lean Thinking na construção (Opportunities for the application of lean thinking in construction- in Portuguese). Ambiente Construído, v. 3, n. 1, p. 7-23.

Rother, M. and Shook, J. (2003) Learning to see: Value stream mapping to create value and eliminate muda. The Lean Enterprise Institute, Cambridge, MA. Version 1.3., June 2003.

Rosenbaum, S; Toledo, M; González, V. (2014). "Improving environmental and production performance in construction projects using value-stream mapping: case study.” Journal of Construction Engineering and Management, 140 (2) p.1-11.

Shou, W., Wang, J., Wang, X. ; Chong, H. (2016). "Examining the critical success factors in the adoption of value stream mapping." In: Annual Conference of the International Group for Lean Construction, 24, 2016. Proceedings... Boston: IGLC.

Womack, J; Jones, D. (1998). Lean thinking: banish waste and create wealth in your corporation. New York: Simon and Schuster.

Yin, R. K. (1994). Case study research: Design and methods. Thousand Oaks, CA: Sage.

Yu, H., Tweed, T., Al-Hussein, M., and Nasseri, R. (2009). "Development of lean model for house construction using value stream mapping." Journal of Construction Engineering and Management, (782), 782-790. 